\title{
The impact of body temperature abnormalities on the disease severity and outcome in patients with severe sepsis: an analysis from a multicenter, prospective survey of severe sepsis
}

\author{
Shigeki Kushimoto ${ }^{1 *}$, Satoshi Gando ${ }^{2}$, Daizoh Saitoh ${ }^{3}$, Toshihiko Mayumi ${ }^{4}$, Hiroshi Ogura ${ }^{5}$, Seitaro Fujishima ${ }^{6}$, \\ Tsunetoshi Araki ${ }^{7}$, Hiroto kkeda $^{8}$, Joji Kotani ${ }^{9}$, Yasuo Miki ${ }^{10}$, Shin-ichiro Shiraishi ${ }^{11}$, Koichiro Suzuki ${ }^{12}$, \\ Yasushi Suzuki $^{13}$, Naoshi Takeyama ${ }^{14}$, Kiyotsugu Takuma ${ }^{15}$, Ryosuke Tsuruta ${ }^{16}$, Yoshihiro Yamaguchi ${ }^{17}$, \\ Norio Yamashita ${ }^{18}$, Naoki Aikawa ${ }^{6}$, JAAM Sepsis Registry (JAAMSR) Study Group
}

\begin{abstract}
Introduction: Abnormal body temperatures $\left(T_{b}\right)$ are frequently seen in patients with severe sepsis. However, the relationship between $T_{b}$ abnormalities and the severity of disease is not clear. This study investigated the impact of $T_{b}$ on disease severity and outcomes in patients with severe sepsis.

Methods: We enrolled 624 patients with severe sepsis and grouped them into 6 categories according to their $T_{b}$ at the time of enrollment. The temperature categories $\left(\leq 35.5^{\circ} \mathrm{C}, 35.6-36.5^{\circ} \mathrm{C}, 36.6-37.5^{\circ} \mathrm{C}, 37.6-38.5^{\circ} \mathrm{C}, 38.6-39.5^{\circ} \mathrm{C}\right.$, $\geq 39.6^{\circ} \mathrm{C}$ ) were based on the temperature data of the Acute Physiology and Chronic Health Evaluation II (APACHE II) scoring. We compared patient characteristics, physiological data, and mortality between groups.

Results: Patients with $\mathrm{T}_{\mathrm{b}}$ of $\leq 36.5^{\circ} \mathrm{C}$ had significantly worse sequential organ failure assessment (SOFA) scores when compared with patients with $T_{b}>37.5^{\circ} \mathrm{C}$ on the day of enrollment. Scores for APACHE II were also higher in patients with $T_{b} \leq 35.5^{\circ} \mathrm{C}$ when compared with patients with $T_{b}>36.5^{\circ} \mathrm{C}$. The 28-day and hospital mortality was significantly higher in patients with $\mathrm{T}_{\mathrm{b}} \leq 36.5^{\circ} \mathrm{C}$. The difference in mortality rate was especially noticeable when patients with $T_{b} \leq 35.5^{\circ} \mathrm{C}$ were compared with patients who had $T_{b}$ of $>36.5^{\circ} \mathrm{C}$. Although mortality did not relate to $T_{b}$ ranges of $\geq 37.6^{\circ} \mathrm{C}$ as compared to reference range of $36.6-37.5^{\circ} \mathrm{C}$, relative risk for 28 -day mortality was significantly greater in patients with $35.6-36.5^{\circ} \mathrm{C}$ and $\leq 35.5^{\circ} \mathrm{C}$ (odds ratio; $2.032,3.096$, respectively). When patients were divided into groups based on the presence $\left(\leq 36.5^{\circ} \mathrm{C}, \mathrm{n}=160\right)$ or absence $\left(>36.5^{\circ} \mathrm{C}, \mathrm{n}=464\right)$ of hypothermia, disseminated intravascular coagulation (DIC) as well as SOFA and APACHE II scores were significantly higher in patients with hypothermia. Patients with hypothermia had significantly higher 28-day and hospital mortality rates than those without hypothermia ( $38.1 \%$ vs. $17.9 \%$ and $49.4 \%$ vs. $22.6 \%$, respectively). The presence of hypothermia was an independent predictor of 28-day mortality, and the differences between patients with and without hypothermia were observed irrespective of the presence of septic shock.
\end{abstract}

Conclusions: In patients with severe sepsis, hypothermia $\left(T_{b} \leq 36.5^{\circ} \mathrm{C}\right)$ was associated with increased mortality and organ failure, irrespective of the presence of septic shock.

Trial registration: UMIN-CTR ID UMIN000008195

\footnotetext{
* Correspondence: kussie@emergency-medicine.med.tohoku.ac.jp ${ }^{1}$ Division of Emergency Medicine, Tohoku University Graduate School of Medicine, Seiryo-machi 1-1, Aoba-ku, Sendai, Miyagi 980-8574, Japan Full list of author information is available at the end of the article
} 


\section{Introduction}

Body temperature $\left(\mathrm{T}_{\mathrm{b}}\right)$ abnormalities are amongst the most commonly noted symptoms of critically ill patients. Fever occurs in approximately half of patients admitted to the ICU and has been associated with adverse outcomes [1]. Fever is one of the most prominent symptoms of infection [2] and it is part of the host acute-phase response to infectious as well as non-infectious inflammatory stimuli [3]. Fever is also believed to be harmful, especially in patients with life-threatening illness, because febrile responses are known to increase the metabolic rate and minutes ventilation and oxygen consumption, and it can have adverse effects on neurological outcomes [4-6]. Fever could also be beneficial because it is believed to reduce bacterial growth, and a higher $\mathrm{T}_{\mathrm{b}}$ is believed to promote the synthesis of antibodies and cytokines, thereby activating immune cells and improving survival [7-9]. Several studies have suggested that suppression of the febrile response with antipyretic drugs could worsen patient outcomes [10,11].

A large epidemiological study that included patients with and without infection reported that the presence of fever per se could not be associated with increased ICU mortality. Nevertheless, fever with $\mathrm{T}_{\mathrm{b}} \geq 39.5^{\circ} \mathrm{C}$ was associated with a significant increase in mortality $(20.3 \%$ versus $12.0 \%(P<0.001)$ for patients with $\mathrm{T}_{\mathrm{b}} \geq 39.5^{\circ} \mathrm{C}$ and $<39.5^{\circ} \mathrm{C}$, respectively). These very high fevers could be complicated with cardiac arrhythmias, tachycardia, increased oxygen demand, convulsions, and brain damage [1]. A recent study that used data from Australia, New Zealand, and the United Kingdom investigated the association between peak $\mathrm{T}_{\mathrm{b}}$ in the first $24 \mathrm{~h}$ after admission to ICU and inhospital mortality [12]. This study showed that elevated peak $\mathrm{T}_{\mathrm{b}}$ in the first $24 \mathrm{~h}$ in the ICU could be associated with decreased in-hospital mortality in patients with infection. The lowest mortality risk was among patients with $\mathrm{T}_{\mathrm{b}}$ between $39.0^{\circ} \mathrm{C}$ and $39.4^{\circ} \mathrm{C}$. However, mortality risk was increased among patients who did not have infection. Patients with fever in response to non-infective causes may well experience the harmful effects of fever without any fever-related benefits, such as protection against viruses or bacteria.

Hypothermia can be caused by a variety of factors including cold exposure, severe infection, endocrine abnormalities, and drug overdoses, and hypothermic patients require immediate medical intervention [13-15]. Although hypothermia may be an unintended consequence of critical illness and may be associated with an increased risk of mortality in patients with sepsis and non-infectious conditions, the influence of hypothermia on the physiological severity and outcome of critically ill patients, particularly patients with severe sepsis, is not well understood [12,16-22].

Although there are many reports of $\mathrm{T}_{\mathrm{b}}$ abnormalities in patients with sepsis, there is a relative paucity of information on the influences of hyper- or hypothermia on disease severity and outcomes in patients with severe sepsis. The aim of present study was to investigate the association between $\mathrm{T}_{\mathrm{b}}$ and disease severity and patient outcomes in patients with a definitive diagnosis of severe sepsis.

\section{Materials and methods}

This was a prospective study conducted as a part of a multicenter prospective evaluation of severe sepsis in Japan, undertaken by the Japanese Association for Acute Medicine Sepsis Registry (JAAMSR) Study Group [23]. Both the Japanese Association for Acute Medicine and the Ethics Committees of the hospitals that participated in this study approved the study protocol. Data collection was performed as part of the routine clinical examinations without any medical intervention. Data management and statistical analyses were processed anonymously. Based on these reasons, written informed consent was waived by both the Japanese Association for Acute Medicine and the Ethics Committees of the participating hospitals. The study was registered with the University Hospital Medical Information Network Clinical Trials Registry (UMIN-CTR ID: UMIN000008195).

\section{Patients}

Between June 1, 2010, and May 31, 2011, we enrolled 624 patients in this study. All of the patients were diagnosed with severe sepsis and admitted to one of 15 critical care centers in the tertiary care hospitals in Japan. We did not have any exclusion criteria.

\section{Definitions}

Sepsis, severe sepsis, septic shock, and systemic inflammatory response syndrome (SIRS) were defined according to the American College of Chest Physicians/Society of Critical Care Medicine consensus conference and its revised version of 2003 [24,25]. The severity of illness was evaluated according to the acute physiology and chronic health evaluation (APACHE) II score at the time of enrollment [26]. Organ dysfunction was assessed according to the sequential organ failure assessment (SOFA) score [27]. Multiple organ dysfunction syndrome (MODS) was defined as a SOFA score $\geq 12$ [27]. A diagnosis of disseminated intravascular coagulation (DIC) was made on the basis of the scoring system of the International Society on Thrombosis and Haemostasis (ISTH) [28]. The change in fibrin/fibrinogen degradation product (FDP) was used as the fibrin-related marker for the ISTH criteria. FDP values of $<10, \geq 10$ but $<25$, and $\geq 25 \mathrm{mg} / \mathrm{L}$, were defined as no increase, moderate increase, and strong increase, respectively. The outcome measure was the 28-day and hospital allcause mortality. 


\section{Body temperature}

$\mathrm{T}_{\mathrm{b}}$ recorded within $24 \mathrm{~h}$ of a diagnosis of severe sepsis was used for the APACHE II score and the recorded temperature was used in this analysis. We recorded the value measured by the method most preferred by the American College of Critical Care Medicine and the Infectious Diseases Society of America [2]. Although the method used to measure core $\mathrm{T}_{\mathrm{b}}$ was not standardized and the specific methods used for each individual measurement of core $T_{b}$ was not recorded in this survey, all the institutions that participated in this study used standard methods for determining core $\mathrm{T}_{\mathrm{b}}$. The sites used for $\mathrm{T}_{\mathrm{b}}$ measurement at the institutions were as follows: urinary bladder, ten institutions; urinary bladder or rectal, three institutions; rectal, one institution; and intravascular, one institution. To ascertain the effect of $\mathrm{T}_{\mathrm{b}}$ aberrance on disease severity and outcome, patients were grouped into one of six categories based on their core $\mathrm{T}_{\mathrm{b}}$ as recorded for the APACHE II scoring. The categories were $\leq 35.5^{\circ} \mathrm{C}, 35.6$ to $36.5^{\circ} \mathrm{C}, 36.6$ to $37.5^{\circ} \mathrm{C}, 37.6$ to $38.5^{\circ} \mathrm{C}, 38.6$ to $39.5^{\circ} \mathrm{C}$, and $\geq 39.6^{\circ} \mathrm{C}$, as previously reported. A core $\mathrm{T}_{b}$ of $35.5^{\circ} \mathrm{C}$ was taken as the lowest $\mathrm{T}_{\mathrm{b}}$ value because previous studies have reported this temperature as the threshold of hypothermia with high mortality [16,29-34]. Although previous studies considered $35.5^{\circ} \mathrm{C}$ as the threshold for hypothermia [16,29-32], we opted to use $36.5^{\circ} \mathrm{C}$ as the threshold because we found significant differences in the mortality of patients with $\mathrm{T}_{\mathrm{b}} \leq 36.5^{\circ} \mathrm{C}$ compared with those with $\mathrm{T}_{\mathrm{b}}>36.5^{\circ} \mathrm{C}$ based on the results of a temperature categorical analysis, as shown in Tables 1 and 2 . We also compared the mortality of patients divided into two groups using $36.5^{\circ} \mathrm{C}$ as a cutoff value. This analysis demonstrated significant differences between groups in both the 28-day and hospital mortality $(P<0.001)$. Based on these findings, we evaluated the effect of hypothermia defined as $\mathrm{T}_{\mathrm{b}} \leq 36.5^{\circ} \mathrm{C}$ on not only mortality but also disease severity, which may affect mortality. For analysis, patients were divided into two groups, namely, hypothermia $\left(\mathrm{T}_{\mathrm{b}} \leq 36.5^{\circ} \mathrm{C}, \mathrm{n}=160\right)$ and no-hypothermia $\left(\mathrm{T}_{\mathrm{b}}>36.5^{\circ} \mathrm{C}, \mathrm{n}=464\right)$.

\section{Assessments}

Blood was collected at the time of admission to ICU and then daily thereafter as part of the routine clinical and laboratory tests using established standard laboratory techniques. Platelet counts and coagulation variables necessary to diagnose DIC were collected and APACHE II, SOFA, and DIC scores were assessed.

\section{Statistical analysis}

Data are expressed as medians and interquartile ranges. All statistical analyses were performed using SPSS 19.0 for Windows (SPSS, Chicago, IL, USA). Comparisons between the 2 groups were performed using the Mann-
Table 1 Baseline characteristics and outcome of the enrolled patients $(n=624)$

\begin{tabular}{|c|c|}
\hline Characteristic & Value \\
\hline Age, years & $72(61-81)$ \\
\hline Gender, male/female & $391 / 233$ \\
\hline APACHE I| score & $23(17-29)$ \\
\hline SOFA score & $8(6-11)$ \\
\hline MODS, n (\%) & $144(23.1)$ \\
\hline Septic shock, n (\%) & $282(45.2)$ \\
\hline \multicolumn{2}{|l|}{ Admission category } \\
\hline Medical & $519(83.2 \%)$ \\
\hline Trauma & $27(4.3 \%)$ \\
\hline Surgery & 19 (3.0\%) \\
\hline Burns & $19(3.0 \%)$ \\
\hline Other & $40(6.4 \%)$ \\
\hline \multicolumn{2}{|l|}{ Site of Infection } \\
\hline Pulmonary & $261(41.8 \%)$ \\
\hline Intra-abdominal & $133(21.3 \%)$ \\
\hline Urinary & $78(12.5 \%)$ \\
\hline Skin/soft tissue & $78(12.5 \%)$ \\
\hline Meningitis & $15(2.4 \%)$ \\
\hline Catheter-related & $11(1.8 \%)$ \\
\hline Bone/joint & $10(1.6 \%)$ \\
\hline Infective endocarditis & $3(0.5 \%)$ \\
\hline Other & $25(4.0 \%)$ \\
\hline 28-day mortality, n (\%) & $144(23.1 \%)$ \\
\hline Hospital mortality, n (\%) & $184(29.5 \%)$ \\
\hline
\end{tabular}

Values are presented as median (IQR) or number (\%). APACHE, acute physiology and chronic health evaluation; SOFA, sequential organ failure assessment; MODS, multiple organ dysfunction syndrome.

Whitney's U test, and categorical variables were summarized using proportions and compared between groups using either the Pearson's chi-square or Fisher's exact test, where appropriate. Kruskal-Wallis one-way analysis of variance and multiple chi-square tests were used for comparisons between multiple groups, and $P$-values were adjusted with the Bonferroni correction for multiple testing.

Odds ratios (OR) are reported relative to a reference range of $T_{b}$, as previously reported [33]. We defined the reference range here as the $T_{b}$ category of 36.6 to $37.5^{\circ} \mathrm{C}$. Additionally, survival curves were derived by the KaplanMeier method and compared by the log-rank test for each range. We used a multivariate logistic model to assess the relationships between 28-day mortality and independent variables in patients with severe sepsis. Outcome (dead, 1; survived, 0) was used as the criterion variable, and age, gender (male or female), admission category of underlying medical condition (medical or other cause), SOFA score, APACHE II score, positive blood culture (yes or no), the 
Table 2 Body temperature and severity of coagulation abnormality/organ failure scores

\begin{tabular}{|c|c|c|c|c|c|c|}
\hline & & & Body temp & ture, ${ }^{\circ} \mathrm{C}$ & & \\
\hline & $\leq 35.5(n=99)$ & $\begin{array}{c}35.6 \text { to } 36.5 \\
(n=61)\end{array}$ & $\begin{array}{c}36.6 \text { to } 37.5 \\
(n=112)\end{array}$ & $\begin{array}{c}37.6 \text { to } 38.5 \\
(n=155)\end{array}$ & $\begin{array}{c}38.6 \text { to } 39.5 \\
(n=133)\end{array}$ & $\geq 39.6(n=64)$ \\
\hline Age, years & $76(65 \text { to } 82)^{\text {de }}$ & $78(62.5 \text { to } 83.5)^{\text {de }}$ & $75(66 \text { to } 84)^{\text {de }}$ & $72(61 \text { to } 82)^{\text {de }}$ & 67 (58 to 76$)$ & 65 (45.25 to 78.75$)$ \\
\hline Septic shock, n (\%) & $62(62.6 \%)^{\text {bcde }}$ & $33(54.1 \%)$ & $46(41.1 \%)$ & $63(40.6 \%)$ & $54(40.6 \%)$ & $24(37.5 \%)$ \\
\hline SIRS criteria & $4(3 \text { to } 4)^{\mathrm{abc}}$ & $3(2 \text { to } 4)^{\text {bde }}$ & $3(2 \text { to } 3)^{\text {cde }}$ & $3(3 \text { to } 4)^{\text {de }}$ & 4 (3 to 4$)$ & 4 (3 to 4$)$ \\
\hline DIC score & $5(2 \text { to } 6)^{c}$ & $4(2$ to 6$)$ & $4(2$ to 5$)$ & 3 (2 to 5$)$ & $3(2$ to 5$)$ & 3 (2 to 5$)$ \\
\hline $\mathrm{DIC} \geq 5, \mathrm{n}(\%)$ & $28(28.3 \%)^{\text {cde }}$ & $15(24.6 \%)^{c}$ & $22(19.6 \%)$ & $20(12.9 \%)$ & $21(15.8 \%)$ & 7 (10.9\%) \\
\hline SOFA score & $10(7 \text { to } 12)^{\text {cde }}$ & $10(7 \text { to } 13)^{\text {cde }}$ & $8(5$ to 11$)$ & $8(5$ to 11$)$ & $7(5$ to 10.75$)$ & 7 (6 to 10$)$ \\
\hline MODS, n (\%) & $35(35.4 \%)^{\text {cde }}$ & $23(37.8 \%)^{\text {cde }}$ & $27(24.1 \%)$ & $32(20.6 \%)$ & $23(17.3 \%)$ & $10(15.6 \%)$ \\
\hline APACHE ॥ & $28(23 \text { to } 33)^{\text {bcde }}$ & 24 (20 to 29$)$ & 21 (16.25 to 27$)$ & 21 (16 to 27 ) & 22 (17 to 26$)$ & 22 (17.25 to 30$)$ \\
\hline Outcome & & & & & & \\
\hline 28-day mortality, n (\%) & $40(40.4 \%)^{\text {bcde }}$ & $21(34.4 \%)^{\text {cde }}$ & $23(20.5 \%)$ & $28(18.1 \%)$ & $21(15.8 \%)$ & $11(17.2 \%)$ \\
\hline Hospital mortality, n (\%) & $52(52.5 \%)^{\text {bcde }}$ & $27(44.3 \%)^{\text {bcde }}$ & $27(24.1 \%)$ & 39 (25.2\%) & $26(19.5 \%)$ & $13(20.3 \%)$ \\
\hline
\end{tabular}

presence of comorbidity (yes or no), and hypothermia $\left(\mathrm{T}_{\mathrm{b}} \leq 36.5^{\circ} \mathrm{C}\right.$ or $\left.>36.5^{\circ} \mathrm{C}\right)$ were used as explanatory variables. Results are reported as OR, $P$-values, and 95\% CI. Differences with a $P$-value $<0.05$ were considered to be statistically significant. Furthermore, $P<0.0033$ (after Bonferroni correction) was used for comparisons between groups in multiple testing (Table 2).

\section{Results}

\section{Baseline characteristics and patient outcome}

During the 1-year study period, a total of 14,417 patients were admitted to the 15 critical care centers, and 624 (4.3\%) of these patients were diagnosed with severe sepsis and enrolled in this study. The characteristics at enrollment and outcomes of patients are shown in Table 1. The mean age was 69 years, and the mean initial APACHE II score and SOFA scores were 23.4 and 8.6, respectively. The major sites of infection were pulmonary, intra-abdominal, urinary, and skin/soft tissue. More than half of the patients had dysfunction of three or more organ systems. The 28 -day mortality was $23.1 \%$ and the overall hospital mortality was $29.5 \%$. Sepsis-related hospital mortality was $25.6 \%$ (160/624 patients).

\section{Relationships between body temperature and severity scores}

Patients with $\mathrm{T}_{\mathrm{b}}>38.5^{\circ} \mathrm{C}$ were significantly younger than patients with $\mathrm{T}_{\mathrm{b}} \leq 38.5^{\circ} \mathrm{C}$. The prevalence of septic shock was significantly higher among patients with $\mathrm{T}_{\mathrm{b}} \leq 35.5^{\circ} \mathrm{C}$ when compared with the incidence of septic shock among patients in the other $\mathrm{T}_{\mathrm{b}}$ categories (Table 2). MODS and SOFA on the day of enrollment were significantly higher in patients with $\mathrm{T}_{\mathrm{b}} 35.6$ to $36.5^{\circ} \mathrm{C}$ and $\leq 35.5^{\circ} \mathrm{C}$ when compared with patients who had $\mathrm{T}_{\mathrm{b}}>37.5^{\circ} \mathrm{C}$. The
APACHEII scores in patients with $\mathrm{T}_{\mathrm{b}} \leq 35.5^{\circ} \mathrm{C}$ were significantly higher when compared with patients who had $\mathrm{T}_{\mathrm{b}}$ of $>36.5^{\circ} \mathrm{C}$.

For mortality rates, patients who had $\mathrm{T}_{\mathrm{b}} \leq 36.5^{\circ} \mathrm{C}$ had significantly higher 28-day and hospital mortality rates when compared with patients who had $\mathrm{T}_{\mathrm{b}}>36.5^{\circ} \mathrm{C}$. The mortality rate among patients who had $\mathrm{T}_{\mathrm{b}} \leq 35.5^{\circ} \mathrm{C}$ was especially high at $40.4 \%$ and $52.5 \%$ for 28 -day and hospital mortality rates, respectively. The lowest 28 -day and hospital mortality were noted in patients with $\mathrm{T}_{\mathrm{b}}$ between 38.6 and $39.5^{\circ} \mathrm{C}$ (15.8\% and $19.5 \%$, for 28 -day and hospital mortality, respectively) (Table 2).

\section{Body temperature and mortality}

Table 3 shows 28-day mortality and OR for each $\mathrm{T}_{\mathrm{b}}$ (taken on day 1) relative to the reference range of 36.6 to $37.5^{\circ} \mathrm{C}$. We found no relationships between mortality and $\mathrm{T}_{\mathrm{b}}$ in patients in the following categories: 37.6 to $38.5^{\circ} \mathrm{C}, 38.6$ to $39.5^{\circ} \mathrm{C}$, and $\geq 39.6^{\circ} \mathrm{C}$. The relationship between mortality and $\mathrm{T}_{\mathrm{b}}$ was significant in patients in the $\mathrm{T}_{\mathrm{b}}$ categories of 35.6 to $36.5^{\circ} \mathrm{C}(\mathrm{OR} 2.032, P=0.047)$ and $\leq 35.5^{\circ} \mathrm{C}$ (OR 3.096, $P=0.001$ ). Kaplan-Meier estimates for the probability of survival at 28 days were lower in patients

Table 3 Day-1 body temperature and 28-day mortality

\begin{tabular}{ccccc}
\hline $\begin{array}{c}\text { Range of body } \\
\text { temperature }\left({ }^{\circ} \mathrm{C}\right)\end{array}$ & $\begin{array}{c}\text { 28-day } \\
\text { mortality }\end{array}$ & $\begin{array}{c}\text { Unadjusted } \\
\text { odds ratio }\end{array}$ & $\mathbf{9 5 \% ~ C l}$ & $\boldsymbol{P}$-value \\
\hline$\leq 35.5$ & $40.4 \%$ & 3.096 & $1.611,5.947$ & 0.001 \\
35.6 to 36.5 & $34.4 \%$ & 2.032 & $1.009,4.088$ & 0.047 \\
36.6 to 37.5 & $20.5 \%$ & 1.000 & (reference) & \\
37.6 to 8.5 & $18.1 \%$ & 0.853 & $0.461,1.577$ & 0.621 \\
38.6 to 39.5 & $15.8 \%$ & 0.726 & $0.377,1.395$ & 0.404 \\
$\geq 39.6$ & $17.2 \%$ & 0.803 & $0.363,1.778$ & 0.693 \\
\hline
\end{tabular}


with $\mathrm{T}_{\mathrm{b}}$ between $35.6^{\circ} \mathrm{C}$ and $36.5^{\circ} \mathrm{C}$ and $\leq 35.5^{\circ} \mathrm{C}$ compared to patients who had $\mathrm{T}_{\mathrm{b}} \geq 36.6^{\circ} \mathrm{C}$ (Figure 1).

Severity scores and outcome in hypothermic and nonhypothermic patients

After analyzing the data for the different $\mathrm{T}_{\mathrm{b}}$ categories, we defined $36.5^{\circ} \mathrm{C}$ as the threshold temperature for hypothermia and compared variables and outcomes between patients with hypothermia $\left(\leq 36.5^{\circ} \mathrm{C}, \mathrm{n}=160\right)$ and those without hypothermia $\left(>36.5^{\circ} \mathrm{C}, \mathrm{n}=464\right)$.

The incidence of septic shock was significantly higher in patients with hypothermia compared to patients without hypothermia. DIC, SOFA, and APACHE II scores and the incidence of MODS were significantly increased among hypothermic patients (Table 4). In hypothermic patients, 28-day and hospital mortality were higher (more than double) than the mortality rates of patients without hypothermia (38.1\% versus $17.9 \%$, 49.4\% versus $22.6 \%$, for 28 -day and for hospital mortality, respectively) (Table 4).

Comparisons of severity scores and outcome between hypothermic and non-hypothermic patients with and without septic shock

The incidence of septic shock was significantly higher in patients with hypothermia. We separately evaluated the

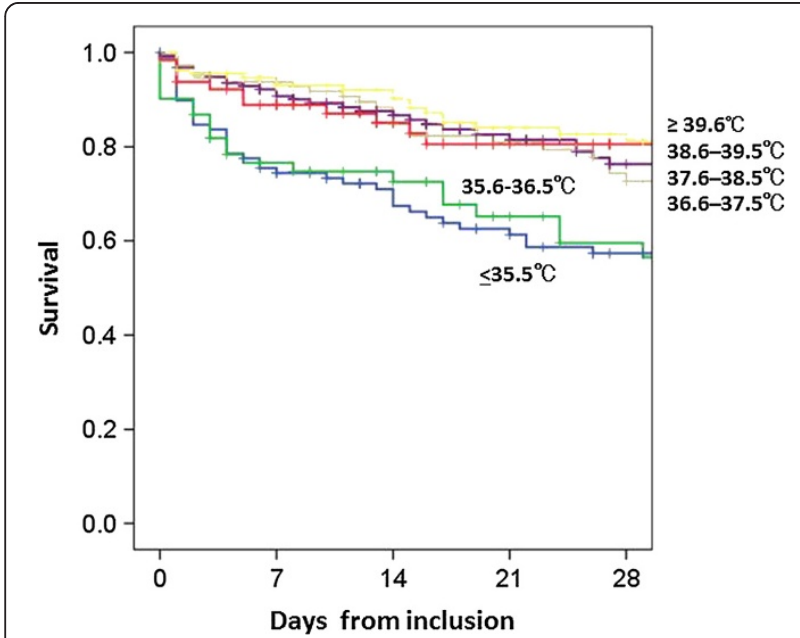

Figure 1 Body temperature within $24 \mathrm{~h}$ of ICU admission and survival of patients with severe sepsis. This figure depicts the Kaplan-Meier estimates for the probability of survival, which at 28 days was lower in patients with body temperature of $\leq 35.5^{\circ} \mathrm{C}$ and 35.6 to $36.5^{\circ} \mathrm{C}$, as compared to patients with body temperatures of 36.6 to $37.5^{\circ} \mathrm{C}, 37.6$ to $38.5^{\circ} \mathrm{C}, 38.6$ to $39.5^{\circ} \mathrm{C}$, and $\geq 39.6^{\circ} \mathrm{C}(P<0.001)$. Body temperature was recorded as the highest score on the acute physiology and chronic health evaluation (APACHE) II scoring system and as the farthest value from 36.5 to $37.0^{\circ} \mathrm{C}$ within $24 \mathrm{~h}$ from the time of enrollment, which was divided into categorical variables with $1{ }^{\circ} \mathrm{C}$ increments. Thus, body temperature was analyzed in six range categories: $\leq 35.5^{\circ} \mathrm{C}, 35.6$ to $36.5^{\circ} \mathrm{C}, 36.6$ to $37.5^{\circ} \mathrm{C}, 37.6$ to $38.5^{\circ} \mathrm{C}, 38.6$ to $39.5^{\circ} \mathrm{C}$, and $\geq 39.6^{\circ} \mathrm{C}$.
Table 4 Characteristics, physiology on day 1 and outcome in hypothermic (body temperature $\leq 36.5^{\circ} \mathrm{C}$ ) and non-hypothermic severe sepsis patients

\begin{tabular}{cccc}
\hline & $\begin{array}{c}\text { Hypothermia } \\
\text { (n= 160) }\end{array}$ & $\begin{array}{c}\text { Non-hypothermia } \\
\text { (n= 464) }\end{array}$ & P-value \\
\hline Age, years & $76(64.25$ to 83$)$ & $71(60$ to 80$)$ & 0.001 \\
Septic shock & $59.4 \%(n=95)$ & $40.3 \%(n=187)$ & $<0.001$ \\
DIC score & $4(2$ to 6$)$ & $3(2$ to 5$)$ & 0.009 \\
SOFA score & $10(7$ to 13$)$ & $8(5$ to 11$)$ & $<0.001$ \\
APACHE II score & $26(21$ to 32$)$ & $21(16.25$ to 27$)$ & $<0.001$ \\
Outcome & & & \\
28-day mortality & $38.1 \%(n=61)$ & $17.9 \%(n=83)$ & $<0.001$ \\
Hospital mortality & $49.4 \%(n=79)$ & $22.6 \%(n=105)$ & $<0.001$ \\
\hline
\end{tabular}

Results are presented as median (IQR) or \% (number). DIC, disseminated intravascular coagulation; SOFA, sequential organ failure assessment; APACHE, acute physiology and chronic health evaluation.

influence of hypothermia on variables and outcomes in patients with and without septic shock, because mortality and severity scores in patients with septic shock were significantly higher when compared with other patients [23]. Patients with septic shock had higher DIC, SOFA, and APACHE II scores if they were hypothermic at the time of diagnosis. In these hypothermic patients, both 28-day and hospital mortality were nearly twice those of patients with septic shock and no hypothermia (Table 5).

In patients without septic shock, hypothermic patients had a significantly higher incidence of MODS and they also had significantly higher SOFA and APACHE II scores when compared with patients who did not have hypothermia. Although the 28-day mortality was not significantly different between hypothermic and nonhypothermic patients, hospital mortality in hypothermic patients was nearly twice that of non-hypothermic patients (30.8\% versus $17.0 \%$ ) (Table 6). The 28 -day and hospital mortality rates in hypothermic patients without

Table 5 Characteristics, physiology on day 1, and outcome in hypothermic (body temperature $\leq 36.5^{\circ} \mathrm{C}$ ) and non-hypothermic patients with septic shock

\begin{tabular}{cccc}
\hline & $\begin{array}{c}\text { Hypothermia } \\
(\mathbf{n}=\mathbf{9 5})\end{array}$ & $\begin{array}{c}\text { Non-hypothermia } \\
(\mathbf{n}=187)\end{array}$ & $\boldsymbol{P}$-value \\
\hline Age, years & $75(62$ to 83$)$ & $72(61$ to 79$)$ & 0.069 \\
DIC score & $4.0(2.0$ to 5.0$)$ & $3.0(2.0$ to 5.0$)$ & 0.047 \\
SOFA score & $11.0(9.0$ to 13.0$)$ & $10.0(8.0$ to 13.0$)$ & 0.039 \\
APACHE II score & $29.0(23.0$ to 35.0$)$ & $25.0(19.0$ to 31.0$)$ & 0.001 \\
Outcome & & & \\
28-day mortality & $49.5 \%(n=47)$ & $24.6 \%(n=46)$ & $<0.001$ \\
Hospital mortality & $62.1 \%(n=59)$ & $31.0 \%(n=58)$ & $<0.001$ \\
\hline
\end{tabular}

Results are presented as median (IQR) or \% (number). DIC, disseminated intravascular coagulation; SOFA, sequential organ failure assessment; APACHE, acute physiology and chronic health evaluation. 
Table 6 Characteristics, physiology on day 1, and outcome in hypothermic (body temperature $\leq 36.5^{\circ} \mathrm{C}$ ) and non-hypothermic patients without septic shock

\begin{tabular}{cccc}
\hline & $\begin{array}{c}\text { Hypothermia } \\
\text { (n= 65) }\end{array}$ & $\begin{array}{c}\text { Non-hypothermia } \\
\text { (n= 277) }\end{array}$ & P-value \\
\hline Age, years & $78(70$ to 82.5$)$ & $71(58$ to 81$)$ & 0.004 \\
DIC score & $3(2$ to 5$)$ & $3(2$ to 5$)$ & 0.133 \\
SOFA score & $7.5(5$ to 11$)$ & $6(4$ to 8$)$ & 0.004 \\
APACHEll score & $24(18$ to 27$)$ & $19(15$ to 24$)$ & $<0.001$ \\
Outcome & & & \\
28-day mortality & $21.5 \%(n=14)$ & $13.4 \%(n=37)$ & 0.096 \\
Hospital mortality & $30.8 \%(n=20)$ & $17.0 \%(n=47)$ & 0.012 \\
\hline
\end{tabular}

DIC, disseminated intravascular coagulation; SOFA, sequential organ failure assessment; APACHE, acute physiology and chronic health evaluation. Results are presented as median (IQR) or \% (number).

septic shock and non-hypothermic patients with septic shock were both double those in patients who were nonhypothermic and did not have septic shock. In addition, the 28-day and hospital mortality rates in hypothermic patients with septic shock were almost four times higher than those in non-hypothermic patients without septic shock.

Table 7 shows that hypothermia, defined as a core $\mathrm{T}_{\mathrm{b}}$ of $\leq 36.5^{\circ} \mathrm{C}$, was an independent predictor of 28 -day mortality in patients with severe sepsis, especially in the presence of septic shock.

\section{Discussion}

The results of this study clearly indicate that the mortality rate amongst patients with severe sepsis is significantly higher among those who have a $\mathrm{T}_{\mathrm{b}}$ of $\leq 36.5^{\circ} \mathrm{C}$ compared to those who have a $\mathrm{T}_{\mathrm{b}}$ of $>36.5^{\circ} \mathrm{C}$ measured within $24 \mathrm{~h}$ of diagnosis. In this study, the mortality rate was more than two times higher among patients with severe sepsis who were hypothermic compared to patients with severe sepsis who had no hypothermia. Furthermore, the higher mortality rate was associated with a deterioration of organ function and DIC. The effect of hypothermia on mortality rate was consistently observed in patients with and without septic shock.

In our study, elevated $\mathrm{T}_{\mathrm{b}}$ was not associated with an increase in disease severity or risk of mortality. Moreover, elevated $T_{b}$ was not associated with a progressive increase in disease severity or mortality when compared with the reference $\mathrm{T}_{\mathrm{b}}$ range of 36.6 to $37.5^{\circ} \mathrm{C}$. Our results suggest that higher $T_{b}$ is not harmful in patients with severe sepsis. Studies investigating the effect of fever control by means of antipyretic treatment or external cooling and the risk of mortality have reported contrasting results, and it is clear that the role of fever and its control in patients with severe sepsis still needs to be elucidated [34,35].

It has been suggested that hypothermia is associated with an increased risk of mortality in critically ill
Table 7 Results of multivariate logistic regression analysis for the prediction of 28-day mortality

\begin{tabular}{lccc}
\hline Factors & Odds ratio & $\boldsymbol{P}$ value & $\mathbf{9 5 \%} \mathbf{C l}$ \\
\hline Severe sepsis ( $\mathrm{n}=602)$ & & & \\
Age & 1.026 & 0.001 & $1.010-1.042$ \\
Gender (male) & 1.476 & 0.091 & $0.940-2.317$ \\
$\begin{array}{l}\text { Admission category } \\
\text { (medical conditions) }\end{array}$ & 1.098 & 0.778 & $0.572-2.109$ \\
SOFA score & & & \\
APACHE II score & 1.111 & 0.002 & $1.041-1.186$ \\
Positive blood culture & 1.062 & 0.000 & $1.029-1.095$ \\
Presence of comorbidity & 1.471 & 0.073 & $0.965-2.242$ \\
Hypothermia (body temperature & 1.952 & 0.003 & $1.253-3.040$ \\
$<36.5^{\circ} \mathrm{C}$ ) & & & \\
Severe sepsis with septic shock ( $\mathrm{n}=273)$ & & & \\
Age & 1.036 & 0.001 & $1.014-1.059$ \\
Gender (male) & 1.676 & 0.095 & $0.914-3.074$ \\
$\begin{array}{l}\text { Admission category } \\
\text { (medical conditions) }\end{array}$ & 1.110 & 0.829 & $0.431-2.860$ \\
SOFA score & & & \\
APACHE II score & 1.078 & 0.119 & $0.981-1.186$ \\
Positive blood culture & 1.050 & 0.019 & $1.008-1.094$ \\
Presence of comorbidity & 1.761 & 0.052 & $0.996-3.114$ \\
Hypothermia (body temperature & 2.778 & 0.001 & $1.555-4.965$ \\
$<36.5^{\circ} \mathrm{C}$ ) & & & \\
\hline
\end{tabular}

$\mathrm{Cl}$, confidence interval; SOFA, Sequential Organ Failure Assessment; APACHE, Acute Physiology and Chronic Health Evaluation; Comorbidity, at least one comorbidity.

patients [12,33]. Moreover, the effect of hypothermia on increased mortality has been shown in patients with and without infection $[12,17,18]$. In the Methylprednisolone Severe Sepsis Study database, the Veterans Administration Systemic Sepsis Cooperative Study of Glucocorticoid Therapy, and the Ibuprofen Sepsis Study, the threshold $\mathrm{T}_{\mathrm{b}}$ for hypothermia was set at $35.5^{\circ} \mathrm{C}$ and patients with severe sepsis were included. The incidence of hypothermia $\left(<35.5^{\circ} \mathrm{C}\right), 28$ - or 30 -day mortality in patients with hypothermia versus patients without hypothermia in these studies were $9 \%, 62 \%$ versus $26 \%$; $10 \%, 57 \%$ versus $28 \%$; and $9.6 \%, 70 \%$ versus $35 \%$, respectively. The NORASEPT II study included only patients with septic shock and the incidence of hypothermia among these patients was $21 \%$. The mortality in patients with hypothermia and in those without hypothermia was $59 \%$ and $34 \%$, respectively. In the present study, the incidence of mortality among patients with $\mathrm{T}_{\mathrm{b}} \leq 35.5^{\circ} \mathrm{C}$ was $15.9 \%$ (99/624 patients), and the 28-day and hospital mortality rates were also significantly higher when compared with other patients $\left(\mathrm{T}_{\mathrm{b}}>35.5^{\circ} \mathrm{C} ; 40.4 \%\right.$ versus $19.8 \%, 52.5 \%$ versus $25.1 \%$, for 28 -day and hospital mortality, respectively). Although the underlying mechanism of sepsis-related 
hypothermia is still unclear, our results are consistent with previous studies [16,29-32].

We defined $36.5^{\circ} \mathrm{C}$ as the threshold of hypothermia based on the results of our evaluation of the outcomes for the different $\mathrm{T}_{\mathrm{b}}$ categories. We also generated the receiver operating characteristic curves using $\mathrm{T}_{\mathrm{b}}$ on the day of enrollment for the 28-day and hospital mortality evaluation. The analysis revealed that the cutoff values for predicting the 28-day and hospital mortality were $36.9^{\circ} \mathrm{C}$ and $36.3^{\circ} \mathrm{C}$, respectively, for maximizing both sensitivity and specificity (data not shown), and these suggest a $\mathrm{T}_{\mathrm{b}}$ of $36.5^{\circ} \mathrm{C}$ as an acceptable cutoff value to define hypothermia in this study.

Although the impact of hypothermia, defined as a threshold temperature of $35.5^{\circ} \mathrm{C}$, on mortality has been demonstrated in previous studies [16,29-32], the effect of hypothermia on disease severity has not been fully evaluated. Therefore, we evaluated the effects of $T_{b} \leq 36.5^{\circ} \mathrm{C}$ on both mortality and disease severity by comparing patients with and without hypothermia. The incidence of organ failure, DIC and outcomes were significantly different in patients with $\mathrm{T}_{\mathrm{b}}$ of $\leq 36.5^{\circ} \mathrm{C}$ compared to those with $\mathrm{T}_{\mathrm{b}}$ of $>36.5^{\circ} \mathrm{C}$, and there was no significant difference between patients who had $\mathrm{T}_{\mathrm{b}}$ of $\leq 35.5^{\circ} \mathrm{C}$ compared to those with a $\mathrm{T}_{\mathrm{b}}$ of $>35.5^{\circ} \mathrm{C}$. Therefore, $36.5^{\circ} \mathrm{C}$ was considered the threshold for hypothermia in patients with severe sepsis, irrespective of the presence of septic shock.

It is important to note that the inclusion of $\mathrm{T}_{\mathrm{b}}$ abnormalities as a measure of the severity of illness varies between different scoring systems. APACHE II assigns points for patients with either high or low $\mathrm{T}_{\mathrm{b}}$, SAPS II only assigns points for high $\mathrm{T}_{\mathrm{b}}$, and SAPS III only assigns points for low $\mathrm{T}_{\mathrm{b}}[26,36,37]$. Although it is widely accepted that fever has an adverse effect on patients with neurologic injury [38], little is known about the impact of temperature abnormalities on the outcome of other ICU patients, especially patients with sepsis $[1,18]$. The results of this study add valuable knowledge with regard to the influence of $\mathrm{T}_{\mathrm{b}}$ abnormalities on the outcome of patients with severe sepsis. From our results, it is clear that hypothermia has a greater impact on organ dysfunction and outcomes. Thus far, the mechanism underlying the harmful effects of hypothermia is not yet known, but it is evident that hypothermia is more important than elevated temperature for the severity of illness scores in patients with severe sepsis.

\section{Limitations}

There are some limitations to our study. $\mathrm{T}_{\mathrm{b}}$ was recorded within $24 \mathrm{~h}$ of a diagnosis of severe sepsis as the highest core $T_{b}$ value of the APACHE II score. However, we did not standardize the method by which core $T_{b}$ was measured, and we did not attempt to differentiate between patients who had an elevated $T_{b}$ as a result of hyperthermia syndrome or because of fever. Although some patients might have been categorized differently if we employed a systematic protocol for measuring $\mathrm{T}_{\mathrm{b}}$, our recorded core $\mathrm{T}_{\mathrm{b}}$ data were not merely arbitrary values obtained within the $24-\mathrm{h}$ period after a diagnosis of severe sepsis, but these measurements were assessed objectively. In addition, the outcome and influence of treatment may vary significantly on that basis.

We did not specifically control for therapeutic modalities that may have influenced $\mathrm{T}_{\mathrm{b}}$, such as antipyretic drugs or active external temperature control strategies. Although it is widely accepted that temperature control improves outcome in patients with neurologic injury, the effect of acetaminophen, ibuprofen, or external control on the outcome of other critically ill patients is not well understood.

\section{Conclusions}

$\mathrm{T}_{\mathrm{b}}$ of patients with severe sepsis, as measured at the time of diagnosis, significantly affected patient outcome. In our study, hypothermia $\left(\leq 36.5^{\circ} \mathrm{C}\right)$ was associated with a significantly higher risk of mortality. The risk of mortality was almost double among hypothermic patients compared to patients without hypothermia. Hypothermia was also associated with a significant physiological decline in these patients, irrespective of whether they experienced septic shock or not. Elevated $T_{b}$ was not associated with an increased disease severity and risk of mortality.

\section{Key messages}

- In patients with severe sepsis, the impact of elevated body temperature and hypothermia on mortality and severity of physiologic decline is different.

- Hypothermia, defined as body temperature of $\leq 36.5^{\circ} \mathrm{C}$, is significantly associated with an increased mortality risk of more than double that of non-hypothermic patients; moreover, it is associated with a physiological decline in severe sepsis, irrespective of the presence of septic shock.

- Elevated body temperature was not associated with increased disease severity or risk of mortality.

\section{Abbreviations}

APACHE: Acute physiology and chronic health evaluation; DIC: Disseminated intravascular coagulation; FDP: Fibrin/fibrinogen degradation product;

ISTH: International Society on Thrombosis and Haemostasis; JAAM: Japanese Association for Acute Medicine; JAAMSR: Japanese Association for Acute Medicine Sepsis Registry; MODS: Multiple organ dysfunction syndrome; OR: Odds ratio; SAPS: Simplified acute physiology score; SIRS: Systemic inflammatory response syndrome; SOFA: Sequential organ failure assessment; $\mathrm{T}_{\mathrm{b}}$ : Body temperature.

Competing interests

The authors declare that they have no competing interests.

\section{Authors' contributions}

SK participated in study design and data collection and interpretation, performed the statistical analysis, and drafted the manuscript. SG, DS, HO, 
NT, SF, TM, TA, HI, JK, YM, SS, KS, YS, KT, RT, YY, NY, and NA participated in study design and data collection and interpretation, performed the statistical analysis, and helped to draft the manuscript. All authors read and approved the final version of the manuscript.

\section{Acknowledgements}

This study was funded and supported by the Japanese Association for Acute Medicine. This study was approved by the Japanese Association for Acute Medicine and by the following institutional review boards or ethics committees of each hospital: Institutional Review Board of Hokkaido University Hospital for Clinical Research; Ethics Committee of Nagoya University of Graduate School of Medicine; Ethics Committee of Keio University School of Medicine; Fujita Health University ethical review board for epidemiological and clinical studies; Teikyo University Review Board; Ethics Committee of Nippon Medical School Hospital; Ethics Committee of Nippon Medical School Hospital; Center for Clinical Research, Yamaguchi University Hospital; The Ethics Review Board of Hyogo College of Medicine; Ethics Committee of Osaka University Hospital; Ethics Committee of Kyorin University; Ethics Committee of Tohoku University Hospital; Ethics Committee of Kawasaki Municipal Hospital; The Ethical Committee of Kurume University; and Research Ethics Committee of Kawasaki Medical School and Hospital.

\section{Author details}

'Division of Emergency Medicine, Tohoku University Graduate School of Medicine, Seiryo-machi 1-1, Aoba-ku, Sendai, Miyagi 980-8574, Japan. ${ }^{2}$ Division of Acute and Critical Care Medicine, Department of Anesthesiology and Critical Care Medicine, Hokkaido University Graduate School of Medicine, Kita 2-jou Nishi 5, Kitaku, Sapporo-shi, Hokkaido 060-8638, Japan. ${ }^{3}$ Division of Traumatology, Research Institute, National Defense Medical College, 3-2 Namiki, Tokorozawa-shi, Saitama 359-8513, Japan. ${ }^{4}$ Emergency Center, Department of Emergency and Critical Care Medicine, Ichinomiya Municipal Hospital, Bunkyo 2-2-22, Ichinomiya-shi, Aichi 491-8558, Japan. ${ }^{5}$ Department of Traumatology and Acute Critical Medicine, Osaka University Graduate School of Medicine, 2-15 Yamadaoka, Suita-shi, Osaka 565-0871, Japan. ${ }^{6}$ Department of Emergency \& Critical Care Medicine, School of Medicine, Keio University, Shinanomachi 35, Shinjukuku, Tokyo 160-8582, Japan. ${ }^{7}$ Department of Emergency \& Critical Care Medicine, Trauma Center St. Mary's Hospital, Tsubukuhonmachi 422, Kurume-shi, Fukuoka 830-8543, Japan. ${ }^{8}$ Department of Emergency Medicine, Trauma and Resuscitation Center, Teikyo University School of Medicine, Kaga 2-11-1, Itabashiku, Tokyo 173-8606, Japan. ${ }^{9}$ Department of Emergency, Critical Care and Disaster Medicine, Hyogo College of Medicine, Mukogawa-cho 1-1, Nishinomiya-shi, Hyogo 663-8501, Japan. ${ }^{10}$ Advanced Critical Care Center Aichi Medical University Hospital, Yazakokarimata 1-1, Nagakute-shi, Aichi 480-1195, Japan. ${ }^{11}$ Department of Emergency and Critical Care Medicine, Nippon Medical School, Sendagi 1-1-5, Bunkyouku, Tokyo 113-8603, Japan. ${ }^{12}$ Department of Acute Medicine, Kawasaki Medical School, Matsushima 577, Kurashiki-shi, Okayama 701-0114, Japan. ${ }^{13}$ Department of Critical Care Medicine, Iwate Medical University, Uchimaru 19-1, Morioka-shi, Iwate 020-8505, Japan. ${ }^{14}$ Department of Emergency and Acute Intensive Care Medicine, Fujita Health University, Dengakugakubo 1-98, Kutsukake-cho, Toyoake-shi, Aichi 470-1192, Japan. ${ }^{15}$ Emergency \& Critical Care Center, Kawasaki Municipal Hospital, Shinkawadori 12-1, Kawasakiku, Kawasaki-shi, Kanagawa 210-0013, Japan. ${ }^{16}$ Advanced Medical Emergency \& Critical Care Center, Yamaguchi University Hospital, Minamikogushi 1-1-1, Ube-shi, Yamaguchi 755-8505, Japan. ${ }^{17}$ Department of Trauma \& Critical Care Medicine, Kyorin University, School of Medicine, Shinkawa 6-20-2, Mitaka-shi, Tokyo 181-8611, Japan. ${ }^{18}$ Department of Emergency \& Critical Care Medicine, School of Medicine, Kurume University, Asahimachi 67, Kurume-shi, Fukuoka 830-0011, Japan.

Received: 1 May 2013 Accepted: 31 October 2013

Published: 13 November 2013

\section{References}

1. Laupland KB, Shahpori R, Kirkpatrick AW, Ross T, Gregson DB, Stelfox HT: Occurrence and outcome of fever in critically ill adults. Crit Care Med 2008, 36:1531-1535.

2. O'Grady NP, Barie PS, Bartlett JG, Bleck T, Carroll K, Kalil AC, Linden P, Maki DG, Nierman D, Pasculle W, Masur H: American college of critical care medicine, infectious diseases society of America: guidelines for evaluation of new fever in critically ill adult patients: 2008 update from the American college of critical care medicine and the infectious diseases society of America. Crit Care Med 2008, 36:1330-1349.

3. Hawksworth JS, Leeser D, Jindal RM, Falta E, Tadaki D, Elster EA: New directions for induction immunosuppression strategy in solid organ transplantation. Am J Surg 2009, 197:515-524.

4. Manthous CA, Hall JB, Olson D, Singh M, Chatila W, Pohlman A, Kushner R, Schmidt GA, Wood LD: Effect of cooling on oxygen consumption in febrile critically ill patients. Am J Respir Crit Care Med 1995, 151:10-14.

5. The Hypothermia after Cardiac Arrest Study Group: Mild therapeutic hypothermia to improve the neurologic outcome after cardiac arrest. N Engl J Med 2002, 346:549-556.

6. Bernard SA, Gray TW, Buist MD, Jones BM, Silvester W, Gutteridge G, Smith K: Treatment of comatose survivors of out-of-hospital cardiac arrest with induced hypothermia. N Engl J Med 2002, 346:557-563.

7. Villar J, Ribeiro SP, Mullen JB, Kuliszewski M, Post M, Slutsky AS: Induction of the heat shock response reduces mortality rate and organ damage in a sepsis-induced acute lung injury model. Crit Care Med 1994, 22:914-921

8. Kluger MJ, Kozak W, Conn CA, Leon LR, Soszynski D: The adaptive value of fever. Infect Dis Clin North Am 1996, 10:1-20.

9. Mackowiak PA: Fever: blessing or curse? A unifying hypothesis. Ann Intern Med 1994, 120:1037-1040.

10. Eyers $S$, Weatherall M, Shirtcliffe P, Perrin K, Beasley R: The effect on mortality of antipyretics in the treatment of influenza infection: systematic review and meta-analysis. J R Soc Med 2010, 103:403-411.

11. Brandts $\mathrm{CH}$, Ndjavé M, Graninger W, Kremsner PG: Effect of paracetamo on parasite clearance time in Plasmodium falciparum malaria. Lancet 1997, 350:704-709.

12. Young PJ, Saxena M, Beasley R, Bellomo R, Bailey M, Pilcher D, Finfer S, Harrison D, Myburgh J, Rowan K: Early peak temperature and mortality in critically ill patients with or without infection. Intensive Care Med 2012, 38:437-444.

13. Mégarbane B, Axler O, Chary I, Pompier R, Brivet FG: Hypothermia with indoor occurrence is associated with a worse outcome. Intensive Care Med 2000, 26:1843-1849.

14. Brivet F, Carras PM, Dormont J, Guidet B, Offenstadt G, Gachot B, Wolf M, Timsit JF, Misset B: Hypothermia, a pertinent clinical prognostic factor in severe systemic inflammatory response syndrome. Crit Care Med 1994, 22:533-534.

15. Clemmer TP, Fisher CJ Jr, Bone RC, Slotman GJ, Metz CA, Thomas FO: Hypothermia in the sepsis syndrome and clinical outcome. The Methylprednisolone Severe Sepsis Study Group. Crit Care Med 1992, 20:1395-1401

16. Arons MM, Wheeler AP, Bernard GR, Christman BW, Russell JA, Schein R, Summer WR, Steinberg KP, Fulkerson W, Wright P, Dupont WD, Swindell BB: Effects of ibuprofen on the physiology and survival of hypothermic sepsis. Crit Care Med 1999, 27:699-707.

17. Tiruvoipati R, Ong K, Gangopadhyay H, Arora S, Carney I, Botha J: Hypothermia predicts mortality in critically ill elderly patients with sepsis. BMC Geriatr 2010, 10:70.

18. Peres Bota D, Lopes Ferreira F, Melot C, Vincent JL: Body temperature alterations in the critically ill. Intensive Care Med 2004, 30:811-816.

19. Karalapillai D, Story DA, Calzavacca P, Licari E, Liu YL, Hart GK: Inadvertent hypothermia and mortality in postoperative intensive care patients: retrospective audit of 5050 patients. Anaesthesia 2009, 64:968-972.

20. Laupland KB, Davies HD, Church DL, Louie TJ, Dool JS, Zygun DA, Doig CJ: Bloodstream infection-associated sepsis and septic shock in critically ill adults: A population-based study. Infection 2004, 32:59-64.

21. den Hartog AW, de Pont AC, Robillard LB, Binnekade JM, Schultz MJ, Horn J: Spontaneous hypothermia on intensive care unit admission is a predictor of unfavorable neurological outcome in patients after resuscitation: An observational cohort study. Crit Care 2010, 14:R121.

22. Capuzzo M, Moreno RP, Jordan B, Bauer P, Alvisi R, Metnitz PG: Predictors of early recovery of health status after intensive care. Intensive Care Med 2006, 32:1832-1838.

23. Ogura H, Gando S, Saitoh D, Takeyama N, Kushimoto S, Fujishima S, Mayumi T, Araki H, Ikeda H, Kotani J, Miki Y, Shiraishi S, Suzuki K, Suzuki Y, Takuma K, Tsuruta R, Yamaguchi Y, Yamashita N, Aikawa N: Epidemiology of severe sepsis in Japan: Results of a multicenter, prospective survey. J Infect Chemother 2013 
24. Members of the American College of Chest Physicians/Society of Critical Care Medicine Consensus Conference committee: American College of Chest Physicians/Society of Critical Care Medicine Consensus Conference: Definition for sepsis and organ failure and guidelines for the use innovative therapies in sepsis. Crit Care Med 1992, 20:864-874.

25. Levy MM, Fink MP, Marshall JC, Abraham E, Angus D, Cook D, Cohen J, Opal SM, Vincent JL, Ramsay G: SCCM/ESICM/ACCP/ATS/SIS: 2001 SCCM/ESICM/ ACCP/ATS/SIS international sepsis definitions conference. Crit Care Med 2003, 31:1250-1256.

26. Knaus WA, Draper EA, Wanger DP, Zimmerman JE: APACHE II: A severity classification system. Crit Care Med 1985, 13:818-829.

27. Ferreira FL, Bota DP, Bross A, Mélot C, Vincent JL: Serial evaluation of the SOFA score to predict outcome in critically ill patients. JAMA 2001, 286:1754-1758.

28. Taylor FBJ, Toh CH, Hoots WK, Wada H, Levi M: Toward definition, clinical and laboratory criteria, and a scoring system for disseminated intravascular coagulation. Thromb Haemost 2001, 86:1327-1330.

29. Norasept II study investigators, Marik PE, Zaloga GP: Hypothermia and cytokines in septic shock. Intensive Care Med 2000, 26:716-721.

30. Clemmer TP, Fisher CJ Jr, Bone RC, Slotman GJ, Metz CA, Thomas FO: Hypothermia in the sepsis syndrome and clinical outcome. Crit Care Med 1992, 20:1395-1401.

31. Anonymous: Effect of high dose glucocorticoid therapy on mortality in patients with clinical signs of systemic sepsis. The veterans administration systemic sepsis cooperative study group. N Engl J Med 1987, 11:659-665.

32. Sprung CL, Peduzzi PN, Shatney $\mathrm{CH}$, Schein RM, Wilson MF, Sheagren JN, Hinshaw LB: Impact of encephalopathy on mortality in the sepsis syndrome. Crit Care Med 1990, 18:801-806.

33. Laupland KB, Zahar JR, Adrie C, Schwebel C, Goldgran-Toledano D, Azoulay E, Garrouste-Orgeas M, Cohen Y, Jamali S, Souweine B, Darmon M, Timsit JF: Determinants of temperature abnormalities and influence on outcome of critical illness. Crit Care Med 2012, 40:145-151.

34. Lee BH, Inui D, Suh GY, Kim JY, Kwon JY, Park J, Tada K, Tanaka K, letsugu K, Uehara K, Dote K, Tajimi K, Morita K, Matsuo K, Hoshino K, Hosokawa K, Lee KH, Lee KM, Takatori M, Nishimura M, Sanui M, Ito M, Egi M, Honda N, Okayama N, Shime N, Tsuruta R, Nogami S, Yoon SH, Fujitani S, Koh SO, Takeda S, Saito S, Hong SJ, Yamamoto T, Yokoyama T, Yamaguchi T, Nishiyama T, Igarashi T, Kakihana Y, Koh Y: Fever and Antipyretic in Critically ill patients Evaluation (FACE) Study Group: Association of body temperature and antipyretic treatments with mortality of critically ill patients with and without sepsis: multi-centered prospective observational study. Crit Care 2012, 16:R33.

35. Schortgen F, Clabault K, Katsahian S, Devaquet J, Mercat A, Deye N, Dellamonica J, Bouadma L, Cook F, Beji O, Brun-Buisson C, Lemaire F, Brochard L: Fever control using external cooling in septic shock: a randomized controlled trial. Am J Respir Crit Care Med 2012, 185:1088-1095

36. Le Gall JR, Lemeshow S, Saulnier F: A new simplified acute physiology score (SAPS II) based on a European/north American multicenter study. JAMA 1993, 270:2957-2963.

37. SAPS 3 Investigators, Moreno RP, Metnitz PG, Almeida E, Jordan B, Bauer $P$, Campos RA, lapichino G, Edbrooke D, Capuzzo M, Le Gall JR: SAPS 3-From evaluation of the patient to evaluation of the intensive care unit. Part 2: Development of a prognostic model for hospital mortality at ICU admission. Intensive Care Med 2005, 31:1345-1355.

38. Diringer MN, Reaven NL, Funk SE, Uman GC: Elevated body temperature independently contributes to increased length of stay in neurologic intensive care unit patients. Crit Care Med 2004, 32:1489-1495.

doi:10.1186/cc13106

Cite this article as: Kushimoto et al:: The impact of body temperature abnormalities on the disease severity and outcome in patients with severe sepsis: an analysis from a multicenter, prospective survey of severe sepsis. Critical Care 2013 17:R271.

\section{Submit your next manuscript to BioMed Central and take full advantage of:}

- Convenient online submission

- Thorough peer review

- No space constraints or color figure charges

- Immediate publication on acceptance

- Inclusion in PubMed, CAS, Scopus and Google Scholar

- Research which is freely available for redistribution

Submit your manuscript at www.biomedcentral.com/submit
C BioMed Central 